\title{
Prevalence of and risk factors associated with latent tuberculosis infection in a Latin American region
}

\author{
Javier Andres Bustamante-Rengifo ${ }^{\text {Corresp., } 1}{ }^{1}$, Luz Angela Salazar ${ }^{1}$, Nicole Osorio ${ }^{1}$, Yesica Bejarano ${ }^{2}$, Jose Rafael \\ Tovar $^{2}$, Miryam Astudillo-Hernandez ${ }^{1}$, Maria del Pilar Crespo-Ortiz ${ }^{1}$ \\ 1 Biotechnology and Bacterial Infections Group, Department of Microbiology, Universidad del Valle, Cali, Colombia \\ 2 Department of Statistics, Universidad del Valle, Cali, Colombia \\ Corresponding Author: Javier Andres Bustamante-Rengifo \\ Email address: javier.andres.bustamante@correounivalle.edu.co
}

Tuberculosis (TB) represents a health problem in Colombia, and its control is focused on the search for contacts and treatment of TB cases underscoring the role of latent tuberculosis infection (LTBI) as a reservoir of $M$. tuberculosis. The burden of LTBI in Colombia is unknown. We aimed to estimate the prevalence of LTBI and identify the associated risk factors. In this cross-sectional study, we recruited participants from four health care centers in Cali, Colombia. The participants were eligible if they were aged between 14-70 years, and all participants answered a survey evaluating their medical history and sociodemographic and lifestyle factors. LTBI status was based on tuberculin skin test (TST) positivity using two thresholds: $\geq 10 \mathrm{~mm}$ (TST-10) and $\geq 15 \mathrm{~mm}$ (TST-15). The magnitude of the associations between independent factors and dependent outcomes (LTBI status and TST induration) were evaluated by logistic regression and generalized linear models, respectively. A total of 589 individuals were included with TST positivity rates of $25.3 \%$ (TST-10) and $13.2 \%$ (TST-15). Logistic regression showed that being between age 40 and 69 years [OR $=7.28,95 \% \mathrm{Cl} 1.62-32.7]$, being male [OR $=1.71,95 \%$ $\mathrm{Cl} 1.04-2.84]$, being employed $[\mathrm{OR}=1.56,95 \% \mathrm{Cl} 1.02-2.38]$, and having a low intake of alcohol $[\mathrm{OR}=2.40,95 \% \mathrm{Cl}$ 1.13-5.11] were risk factors for TST positivity, while living in the north zone $[\mathrm{OR}=0.32,95 \% \mathrm{Cl} 0.18-0.55]$, living in the suburb zone $[\mathrm{OR}=0.28,95 \% \mathrm{Cl}$ $0.15-0.52$ ] and having a secondary education $[\mathrm{OR}=0.4995 \% \mathrm{Cl} 0.29-0.83$ ] lowered the risk of TST positivity. The generalized linear model showed that the previous predictors, as well as a low body mass index, had an effect on TST reaction size. The LTBI prevalence found in the population was moderate, reflecting the continuous transmission of $M$. tuberculosis. Social factors seem to play a decisive role in the risk of LTBI. Employed males, who are over 40 years of age, are overweight, have a lower level of education and have a low intake of alcohol (50-100 mL, once/week) should be a priority group for prophylactic treatment as a strategy for TB control in this city. 


\section{Prevalence of and risk factors associated with latent}

2 tuberculosis infection in a Latin American region

3

4

5

6

7

8

Javier Andrés Bustamante-Rengifo ${ }^{1}$, Luz Angela Salazar ${ }^{1}$, Nicole Osorio ${ }^{1}$, Yesica Bejarano ${ }^{2}$, Jose Rafael Tovar ${ }^{2}$, Miryam Astudillo-Hernandez ${ }^{1}$, María del Pilar Crespo-Ortiz ${ }^{1}$

${ }^{1}$ Biotechnology and Bacterial Infections Group, Department of Microbiology, Universidad del Valle, Cali, Colombia.

${ }^{2}$ Department of Statistics, Universidad del Valle, Cali, Colombia.

Corresponding Author:

Javier Andres Bustamante-Rengifo

Cali, Colombia.

Email: javier.andres.bustamante@,correounivalle.edu.co

\section{Abstract}

Tuberculosis (TB) represents a health problem in Colombia, and its control is focused on the search for contacts and treatment of TB cases underscoring the role of latent tuberculosis infection (LTBI) as a reservoir of M. tuberculosis. The burden of LTBI in Colombia is unknown. We aimed to estimate the prevalence of LTBI and identify the associated risk factors. In this cross-sectional study, we recruited participants from four health care centers in Cali, Colombia. The participants were eligible if they were aged between 14-70 years, and all participants answered a survey evaluating their medical history and sociodemographic and lifestyle factors. LTBI status was based on tuberculin skin test (TST) positivity using two thresholds: $\geq 10 \mathrm{~mm}$ (TST-10) and $\geq 15 \mathrm{~mm}$ (TST-15). The magnitude of the associations between independent factors and dependent outcomes (LTBI status and TST induration) were evaluated by logistic regression and generalized linear models, respectively. A total of 589 individuals were included with TST positivity rates of $25.3 \%$ (TST-10) and $13.2 \%$ (TST-15). Logistic regression showed that being between age 40 and 69 years [OR $=7.28,95 \% \mathrm{CI} 1.62-32.7]$, being male [OR $=1.71,95 \% \mathrm{CI}$ 1.04-2.84], being employed [OR $=1.56,95 \% \mathrm{CI} 1.02-2.38]$, and having a low intake of alcohol $[\mathrm{OR}=2.40,95 \%$ CI 1.13-5.11] were risk factors for TST positivity, while living in the north zone $[\mathrm{OR}=0.32,95 \% \mathrm{CI} 0.18-0.55]$, living in the suburb zone $[\mathrm{OR}=0.28,95 \% \mathrm{CI} 0.15-0.52]$ and having a secondary education [OR $=0.4995 \% \mathrm{CI} 0.29-0.83]$ lowered the risk of TST positivity. The generalized linear model showed that the previous predictors, as well as a low body mass index, had an effect on TST reaction size. The LTBI prevalence found in the population was moderate, reflecting the continuous transmission of M. tuberculosis. Social factors seem to play a decisive role in the risk of LTBI. Employed males, who are over 40 years of age, are overweight, have a lower level of education and have a low intake of alcohol (50-100 mL, once/week) should be a priority group for prophylactic treatment as a strategy for $\mathrm{TB}$ control in this city. 


\section{Introduction}

44

45

46

47

48

49

50

51

52

53

54

55

56

57

58

59

60

61

62

63

64

65

66

67

68

69

70

71

72

73

74

75

76

77

78

79

80

81

82

83

84

85

86

87

88
Tuberculosis (TB) is an infectious disease caused by the bacillus Mycobacterium tuberculosis. In the last 200 years TB has killed more than a billion people, and it is the main cause of death due to a single infectious agent (Yap et al., 2018). Antibiotic resistance, lack or poor vaccination campaigns, globalization and poverty have complicated the control of this disease (Dheda et al., 2014; Kargi et al., 2017). In 2018, the World Health Organization (WHO) reported 10 million new TB cases and 1.2 million TB deaths globally. Eighty percent of TB cases and $70 \%$ of deaths occurred in middle-income and low-income countries (WHO, 2019). Coevolution with humans has allowed this microorganism to develop mechanisms to persist within the host for decades (Huynh, Joshi \& Brown, 2011). It is estimated that a quarter of the world's population $(\sim 1.7$ billion or $23 \%$ of people) has latent tuberculosis infection (LTBI) (Houben \& Dodd, 2016), a state of continuous stimulation of the immune system by M. tuberculosis without evidence of clinical symptoms of active disease (Sharma, Mohanan \& Sharma, 2012; Yap et al., 2018). It is thought that $5-10 \%$ of these individuals will progress to active TB within the first two years, and the risk increases in those patients with suppression of cellular immunity by HIV infection, the use of glucocorticoids, blood or organ transplantation, treatment with tumor necrosis factor $\alpha$ inhibitors, malnutrition or diabetes (Basera, Ncayiyana \& Engel, 2017; Chen et al., 2015; Huynh, Joshi \& Brown, 2011; Yap et al., 2018).

The WHO South-East Asia, Western Pacific and Africa regions have an LTBI prevalence above $20 \%$, while the Eastern Mediterranean, Europe and The Americas have an LTBI prevalence lower than $17 \%$. The Americas region has the lowest prevalence of LTBI, with $11 \%$ or approximately 108,000 million infected people (Houben \& Dodd, 2016). However, in the Americas, TB persists as a major public health problem, approximately 282,000 new TB cases are reported every year, and approximately 18,000 people die from this cause (WHO, 2018b). Countries showing the highest morbidity and mortality are Brazil, Peru, Mexico, Haiti and Colombia, representing $68 \%$ of the TB cases in the region (PAHO, 2018).

Colombia is the third most populated country in Latin America with a population of 49 million inhabitants. Despite the country's efforts to control TB, its incidence has increased in the last decade, from 26 cases per 100,000 inhabitants in 2008 (Rodríguez, Gil \& Vera, 2010) to 33 cases per 100,000 in 2018 (WHO, 2018a). Local incidence rates highly differ between regions. Cali, is one of the cities with the highest TB incidence (41 cases per 100,000 inhabitants) which is higher than the national average (26.5 cases per 100,000 inhabitants) (Lesmes Duque \& Reina, 2016; Sivigila, 2017), and Cali has an annual risk of tuberculosis infection (ARTI) of 1.3\%, which is higher than the $0.1 \%$ risk reported for the world population (De la Pava, Salguero \& Alzate, 2002; Hassan \& Diab, 2014). Two contributing factors for this particular setting are a) continued community transmission due to the delay in diagnosing cases of active TB, and b) reactivation of LTBI in vulnerable populations (household TB contacts, prisoners, health care workers, immunocompromised patients, children under 5 years old and the elderly) (Barbosa et al., 2015; del Corral et al., 2009).

LTBI seems to be a reservoir from which active TB will emerge (Abubakar et al., 2018), representing a challenge to the aims of the End TB Strategy ( $90 \%$ reduction in TB incidence by 2035) (Houben \& Dodd, 2016). However, detecting LTBI in humans is difficult. Historically,

Peer] reviewing PDF | (2019:10:41848:1:1:NEW 24 May 2020) 
89

90

91

92

93

94

95

96

97

98

99

100

101

102

103

104

105

106

107

108

109

110

111

112

113

114

115

116

117

118

119

120

121

122

123

124

125

126

127

128

129

130

131

132

133

134

LTBI detection has been performed by assessing the T-cell response against $M$. tuberculosis using the tuberculin skin test (TST) or interferon-gamma release assay (IGRA). These tests are useful to identify people who could benefit from prophylaxis and to control TB incidence and transmission (Abubakar et al., 2018). Nevertheless, both the TST and IGRA have sensitivity and specificity limitations (Muñoz, Stagg \& Abubakar, 2015), and a challenge to understanding how to best use these test is the lack of a gold standard (Stout et al., 2018). Although the evidence shows that both the TST and IGRA can be used for LTBI detection, the availability and affordability of the tests will determine which one should be chosen (WHO, 2018c). In Colombia, the test of choice is the TST, as it requires fewer resources than the IGRA and is more familiar to professionals in clinical settings (Ministry of Health, 2015).

The TST interpretation should consider the presence of immunosuppressive conditions and TB prevalence in the setting, so different cut-off values have been recommended for defining a positive TST: $\geq 5 \mathrm{~mm}$ in immunosuppressed patients and close contact of TB cases and $\geq 10 \mathrm{~mm}$ in healthy individuals living in high-prevalence areas (ATS, 2000; Muñoz, Stagg \& Abubakar, 2015). Considering a possible cross-reactivity with BCG vaccination and non-tuberculosis mycobacterial infections, some authors suggest using a threshold of $15 \mathrm{~mm}$ or more (Abubakar et al., 2018; Shero et al., 2014). In fact, TST reactivity stratified by BCG vaccination status have shown a positive predictive value for the development of TB similar to IGRA (Abubakar et al., 2018), and large TST reactions are more likely to indicate a higher risk of developing active disease (Cao et al., 2019; Moran-Mendoza et al., 2007; Watkins, Brennan \& Plant, 2000). All these considerations must be taken into account when comparing the TST properties between different studies.

There are limited data on the epidemiology and risk of LTBI in the general population, particularly in developing countries. Additionally, LTBI screening is only recommended in target groups and extensive testing of LTBI status in the general population is not affordable (Chen et al., 2015). In Colombia, there is only one published study that describes TST reactivity in the source population (del Corral et al., 2009). For this reason, the aim of this study was to estimate the prevalence of LTBI using two different TST thresholds ( $\geq 10 \mathrm{~mm}$ and $\geq 15 \mathrm{~mm}$ ) and to identify the risk factors associated with a positive TST result and TST induration size. This may allow us to determine the potential size of the current reservoir of infection and to provide information to implement control measures.

\section{Materials and Methods Study design}

This cross-sectional study was conducted from September 27, 2016 to December 1, 2017 in Cali, Colombia. Cali is the third most important city in the country with a population of 2,394,925 inhabitants distributed in 22 districts. The estimated TB incidence is 41 cases per 100,000 inhabitants (Lesmes Duque \& Reina, 2016). The city's public health system is divided into five government social companies (the acronym in Spanish is ESE), and each company provides primary health-care services to different districts by zones, as follows: ESE center (districts 8, 9, 10, 11 and 12), ESE suburb (districts 1, 3, 17, 18, 19, 20 and 22), ESE north (districts 2, 4, 5, 6 and 7), ESE east (districts 13,14,15 and 21) and ESE southeast (district 16). For this study, as a strategy to enroll participants representative of the general population, three reference primary 
135 health-care facilities were selected, one for each ESE except for the ESE east and ESE southeast,

136 which were not included for safety and accessibility reasons. To achieve greater

137 representativeness of the center zone, a secondary-care facility was also included. The selected

138 facilities provide health services to approximately $50 \%$ of the city's low-income population.

139 Healthy individuals attending general medical examinations or the dental service, along their

140

141

142

143

144

145

146

147

148

149

150

151

152

153 companions, were invited to participate in the research.

\section{Participants and data collection}

A total of 1079 volunteers with ages ranging from 14 to 70 years completed a standardized questionnaire including demographic, socioeconomic and clinical data and lifestyle habits. Considering an estimated 42.7\% LTBI (del Corral et al., 2009) with a 95\% confidence level, 4\% precision and 10\% nonresponse rate, the sample size calculated was 647 individuals. Exclusion criteria for this study were a history of chronic diseases (hypertension, diabetes and cancer), previous TB disease or chronic respiratory symptoms, heart disease, advanced liver disease and immunosuppressive conditions (HIV/AIDS infection, transplant and lupus), pregnancy or lactation. These conditions were ruled out to reduce anergy to TST and the risk of severe arm swelling after TST application (Muñoz, Stagg \& Abubakar, 2015). Thus, 629 (58.3\%) subjects were subjected to a TST. However, 589 individuals were included for further study (Fig. 1). Overcrowding was defined as homes with more than three to less than five people per room. Bacillus Calmette-Guérin (BCG) vaccination status was evaluated by visual inspection

156

157 (vaccination scar). The household socioeconomic status (SES) was defined as a composite index developed by an analysis based on characteristics of the dwelling, source of drinking water, type of toilet facilities and features of the neighborhood. The household SES index was categorized into tertiles of (1) extremely-low, (2) low and (3) medium, as this was a population with low resources. A history of smoking was defined as tobacco use in the last 6 months. Alcohol consumption was stratified into 4 levels: high (consumption between 350-750 mL, $\geq 4$ times/week), moderate (consumption between 250-750 mL, 2-3 times/week), low (consumption between 50-100 mL, once/week) and none. Physical activity was defined as yes (exercise every day or $\geq 3$ times/week) or no (never exercise or $<2$ times/week). The body-mass index (BMI) was classified as underweight $\left(<18.5 \mathrm{~kg} / \mathrm{m}^{2}\right)$, normal weight $\left(\geq 18.5\right.$ to $\left.24.9 \mathrm{~kg} / \mathrm{m}^{2}\right)$, overweight ( $\geq 25$ to $29.9 \mathrm{~kg} / \mathrm{m}^{2}$ ) and obesity $\left(\geq 30 \mathrm{~kg} / \mathrm{m}^{2}\right.$ ) according to the classification proposed by the WHO (OMS, 2003). The employment situation was categorized as employee (self-employed workers and subordinate workers) and unemployed (housewives, student or retired).

\section{Ethics statement}

The study protocol was approved by the ethics committee of the Universidad del Valle-CIREH (\#008-015) (Cali, Colombia). All participants provided written informed consent.

\section{Tuberculin skin test}

Five units of tuberculin purified protein derivate (PPD) of M. tuberculosis Mammalian ${ }^{\circledR}(\mathrm{BB}-$ NCIPD Ltd., Sofia, Bulgaria) in $0.1 \mathrm{~mL}$ was injected into in the dorsal surface of the forearm. 180 


\section{Determination of latent infection by $\boldsymbol{M}$. tuberculosis}

182

183

184

185

186

187

188

189

190

191

192

193

194

195

196

197

198

199

200

201

202

203

204

205

206

207

208

209

210

211

212

213

214

215

216

217

218

219

220

221

222

223

224

225

226

Two different thresholds were considered for a positive TST result. An induration of $10 \mathrm{~mm}$ or more (TST-10) and a BCG-dependent induration of $15 \mathrm{~mm}$ or more (TST-15; for the BCG vaccinated participants) were positive according to the current CDC guidelines (ATS, 2000). Given that vaccination actions in Colombia began in the 1960s, regular administration of the BCG vaccine was intensified in the 1970s as part of public health strategies against preventable diseases defined by the PAHO/WHO (Ministry of Health, 2000). For the primary analysis, if the BCG status was unknown, it was assumed that the individuals had been vaccinated (consistent with international recommendations) (Abubakar et al., 2018). All the participants with a positive TST result had a standard anteroposterior and lateral chest radiograph (CXR). LTBI was defined as a positive TST result in the absence of TB respiratory symptoms and normal radiological findings. Active TB was suspected if the individuals had radiological abnormalities, chronic cough (more than 3 weeks), weight loss, night sweats, and fever. All cases with suspected TB were excluded and referred to the tuberculosis program for TB treatment.

\section{Statistical analysis}

Kolmogorov-Smirnov's test revealed that the quantitative data did not follow a normal distribution, so nonparametric statistics were used. Continuous data were compared using the Mann-Whitney U test or Kruskal-Wallis test. Dunn's test was used to analyze variables with more than two categories, and the significance values were adjusted by Bonferroni correction. To analyze the association between LTBI status and the independent variables, Pearson's Chi-square test or Fisher's exact test with odds ratio (OR) and 95\% confidence intervals were used. The trend analysis for TST positivity with increasing age for both males and females was performed using a chi-square test for trend.

Multivariate logistic regression or generalized linear regression models were used to determine the associations between the independent variables and TST positivity or TST induration, respectively. In the logistic regression model, the backward Wald method was used, controlling each factor. The selection of predictors within the model was performed using the likelihood criteria (input $p \leq 0.05$, output $p \geq 0.10$ ). In the generalized linear model, a custom model with a Poisson distribution and a Log link function was used. The model was constructed using the main effects method, and parameter estimates to select the best model were calculated using the Pearson chi-square method accompanied by a robust covariance estimator. The $\beta$ coefficients reported were standardized. For all models, bootstrap analysis was performed with 5000 samples to compare the effect measures obtained in the original model with the bootstrapped model. The analyses were performed using the statistical package SPSS 24.0 (SPSS Inc., Chicago, IL, United States).

\section{Results}

\section{Sociodemographic characteristics and lifestyle habits}

A total of 589 participants were included in this study for a response rate of $54.6 \%$ (Fig. 1). As seen in Table 1, age was classified into 6 groups from 14 to 70 years old. Fifty-five percent of the individuals were in the age range of 40-59 years, and the average age was $43.8 \pm 13.2$ years.

Peer) reviewing PDF | (2019:10:41848:1:1:NEW 24 May 2020) 
227 The females constituted $80 \%$ of the total population. The distribution of the individuals within 228 the three household SES categories was homogeneous ( 30\%). A total of 5.4\% of participants 229 lived in overcrowded areas. More than half of the individuals had completed high school studies, 230 were unemployed, and lived in the northern zone. In relation to the lifestyle of this population, the majority were overweight or obese, did not perform regular physical activity, had no history of smoking or current cigarette consumption, and did not consume alcohol. Only $9 \%$ of the individuals had no visible BCG scar.

\section{Prevalence of latent tuberculosis infection}

The overall prevalence of latent tuberculosis using a threshold $\geq 10 \mathrm{~mm}$ (TST-10) was $25.3 \%$ [149/589; 95\% CI 21.7-28.3\%], and with a threshold $\geq 15 \mathrm{~mm}$ (TST-15) was $13.2 \%$ [78/589; $95 \%$ CI 10.4-15.5\%]. There was a gradual increase in the LTBI prevalence with age, reaching the highest prevalence in the 60-69 years category. The LTBI prevalence was higher in males (33.9\% for TST-10 and $17.8 \%$ for TST-15) (Table 1).

The LTBI prevalence determined by TST-10 and TST-15 was higher in individuals with medium household SES, individual with a primary education level, employees, residents of the central zone, smokers, light drinkers, individual who perform regular physical activity, and overweight and obese individuals. In contrast, no differences were observed in the LTBI prevalence with respect to overcrowding within households or BCG status (Table 1).

\section{Demographic, socioeconomic, and lifestyle factors and their association with TST induration}

The average induration size was signification different between TST + and TST- individual when using either the $\geq 10 \mathrm{~mm}$ (16 $\mathrm{mm}$ vs $2.9 \mathrm{~mm}$ ) or $\geq 15 \mathrm{~mm}$ (19.7 $\mathrm{mm}$ vs $4.2 \mathrm{~mm}$ ) threshold ( $p=$ 0.000 for both), and the mean was located above the cut-off point established for each threshold Independent of threshold, the TST induration size showed an association with multiple variables including age, educational status, employment situation, residence zone, alcohol consumption and BMI (Table 1).

The average induration in individuals under 29 years old was significantly different from that of individuals over 30 years old. Individuals with a primary education level had a higher average TST induration size than individuals with higher education $(p<0.05)$. It was also observed that individuals residing in the center of city presented a higher average in TST induration size compared to individuals residing in the northern $(p=0.000)$ and suburb $(p=0.040)$ zones. Individuals with low alcohol consumption had a greater TST induration size compared to individuals with moderate consumption ( $p=0.006$ ). Regarding BMI, it was initially observed that individuals who were underweight had a lower TST induration that overweight and obese individuals $(p<0.05)$. However, after adjustment of the significance values no statistical differences were observed.

In the generalized linear model, age above 40 years old, residing in the northern or suburb zone, having higher education (secondary and postsecondary), low alcohol consumption and lower BMI showed an association with TST induration. The coefficient of determination found was 
$2730.161(16.1 \%)$. The bootstrapping results confirmed the estimates obtained with the generalized 274 linear regression model. Table 2 shows the standardized $\beta$ coefficients and likelihood values.

275

276

277

278

279

280

281

282

283

284

285

286

287

288

289

290

291

292

293

294

295

296

297

298

299

300

301

302

303

304

305

306

307

308

309

310

311

312

313

314

315

316

317

\section{Demographic, socio-economic, lifestyle factors and their association with TST positivity $(\geq 10 \mathrm{~mm})$}

In the bivariate analysis present in Table 3, when the 14-19 years age category was taken as the reference group, it was found that after the age of 30 years, the risk of LTBI increased significantly, with ORs from 4.31 to 7.78 . In this cross-sectional study, males had a 0.70 -fold higher risk of LTBI than females [OR $=1.70,95 \%$ CI 1.10-2.64]. Meanwhile, as shown in Figure 2, TST-10 positivity increased in males and females with increasing age, a trend that was significant ( $p$ for trend $<0.05$ ). However, the LTBI prevalence in males was significantly higher than in females for the 40-49 years age category [OR $=3.72,95 \%$ CI 1.38-10.03] TST-10 (Table 4). The education distribution showed that a higher education level decreased the risk of LTBI when compared with a primary or lower level [OR $=0.59,95 \% \mathrm{CI} 0.39-0.86$ for secondary]. Being an employee significantly increased the LTBI risk [OR $=1.89,95 \%$ CI 1.30-2.75]. When the risk of LTBI by zone was evaluated with reference to the high prevalence center zone (50\%), it was observed that living in the north or suburb zone decreased the LTBI risk ([OR $=0.29,95 \%$ CI 0.17-0.48] and [OR $=0.27,95 \%$ CI 0.15-0.49], respectively). Low alcohol consumption significantly increased the risk of LTBI [OR $=2.28,95 \%$ CI 1.13-4.59] (Table 3). No association was observed between BCG scar and TST positivity.

In the multivariate logistic regression analysis (Table 5), being age 30 years and above [ORs from 4.29 to 8.30 ], being male [OR $=1.71,95 \% \mathrm{CI} 1.04-2.84]$, being employed [OR $=1.56$, 95\% CI 1.02-2.38] and having a low alcohol consumption $[\mathrm{OR}=2.40,95 \%$ CI 1.13-5.11] were risk factors for LTBI, while living in the north or suburb zone of the city reduced LTBI risk ([OR $=0.32,95 \%$ CI $0.18-0.55]$ and $[\mathrm{OR}=0.28,95 \%$ CI $0.15-0.52]$, respectively). The model had $12.8 \%$ sensitivity and $97.3 \%$ specificity with a Cox \& Snell R-square coefficient of 0.098 $(9.8 \%)$. The bootstrapping results confirmed the estimates obtained with the initial model and corroborated the significance of the predictor (age 30-39 years) within the model.

\section{Demographic, socioeconomic, and lifestyle factors and their association with TST positivity $(\geq 15 \mathrm{~mm})$}

In the bivariate analysis for the TST-15 threshold, only three variables showed an association with TST positivity (Table 3). It was observed that a higher education level (secondary) [OR $=$ $0.52,95 \%$ CI $0.32-0.85]$ and living in the north zone $[\mathrm{OR}=0.22,95 \%$ CI $0.12-0.41]$ or suburb zone $[\mathrm{OR}=0.19,95 \% \mathrm{CI} 0.09-0.38]$ reduced the risk of LTBI. In contrast, low alcohol consumption was a risk factor for LTBI $[\mathrm{OR}=2.34,95 \%$ CI 1.05-5.22]. Although a significant association with TST-15 positivity was not found for any of the age categories or sex, Figure 2 shows an increasing trend in the LTBI prevalence with age that was significant in females $(p=0.036)$ but not in males $(p=0.077)$. However, a positive TST result was more likely in males than in females for the 40-49 years age category [OR $=5.07,95 \%$ CI 1.69-15.1] (Table S1).

In the multivariate analysis (Table 6), in agreement with the regression model obtained for TST10 , it was observed that being male $[\mathrm{OR}=1.76$, CI 95 0.98-3.17] and having a low alcohol 
319

320

321

322

323

324

325

326

327

328

329

330

331

332

333

334

335

336

337

338

339

340

341

342

343

344

345

346

347

348

349

350

351

352

353

354

355

356

357

358

359

360

361

362

363

consumption $[\mathrm{OR}=2.33,95 \% \mathrm{CI} 0.98-5.56]$ increased the risk of LTBI but the association was no significant. However, living in the north zone $[\mathrm{OR}=0.25,95 \%$ CI $0.14-0.47]$ or suburb zone $[\mathrm{OR}=0.19,95 \% \mathrm{CI} 0.09-0.39]$ and having a secondary education level $[\mathrm{OR}=0.4995 \% \mathrm{CI} 0.29$ 0.83 ] were associated with a significant reduction in LTBI risk. The model had $5.1 \%$ sensitivity and $99.0 \%$ specificity with a Cox \& Snell R-square coefficient of 0.069 (6.9\%). The bootstrapping results corroborated the findings of the logistic regression model.

\section{Discussion}

The risk factors associated with the acquisition of LTBI in the general population are rarely reported, and such studies are scarce (Chen et al., 2015; Martinez et al., 2013; Ncayiyana et al., 2016; Yap et al., 2018). This is the first study that evaluated the prevalence of LTBI, and the associated factors in the general population in Colombia, using two thresholds to classify TST positivity. A cut-off point $\geq 10 \mathrm{~mm}$ was used as the main criterion to define the positivity to $M$. tuberculosis infection following CDC guidelines (ATS, 2000), and it was found that LTBI prevalence $(25.3 \%)$ was lower than the reported prevalence in previous studies, which also used the TST, conducted in patients from a trauma unit (38\%) and health care workers $(36.8 \%)$ in Cali, Colombia (Alzate et al., 1993; Barbosa et al., 2015). Compared to population-based studies where TST-10 positivity was the only diagnostic test used to identify $M$. tuberculosis infection, the LTBI prevalence observed in this study was lower than that reported in the source population of Medellín-Colombia (42.7\%) and in urban informal settlements of Lima-Peru (52\%) and Johannesburg-South Africa (34.3\%) (del Corral et al., 2009; Martinez et al., 2013; Ncayiyana et al., 2016) but higher than the estimated prevalence by mathematical models based on estimates of ARI from TST surveys and smear positive TB prevalence for the Americas region (11\%) (Houben \& Dodd, 2016) and that of other countries with a high TB incidence such as China ( $20 \%$ by IGRA in adults of a rural area) and Singapore ( $12.7 \%$ by IGRA in urban area residents) (Chen et al., 2015; Yap et al., 2018). These observations suggest that the LTBI prevalence in urban settlements is high and variable. The differences found with respect to other studies can be partially explained by the type of population. This study excluded participants with any underlying chronic diseases that may predispose them to the infection, and most of the included participants had low and medium household SES.

Considering the possible effect of BCG vaccination on TST specificity, a higher threshold was used $(\geq 15 \mathrm{~mm})$ in individuals who had vaccinated showing a prevalence of $13.2 \%$ that coincides with the LTBI prevalence reported in Singapore (Yap et al., 2018). The use of a TST-15 threshold in some studies has shown a higher likelihood of detecting $M$. tuberculosis infection (Wang et al., 2002) and is a predictor of progression to TB comparable to IGRA (Abubakar et al., 2018). In the present study, it is thought that the effect of vaccination was minimal because, in Colombia, this vaccine is administered in a single dose at birth, and as has been demonstrated, its effect on the outcome of a TST decreases after 15 years (Wang et al., 2002), and $82 \%$ of the participants were over 30 years old. No association was found between the absence of a BCG scar and TST positivity; this observation is in line with that reported in other studies conducted in South Africa, a high TB burden setting where BCG is given at birth, and the TST is performed more than 10 years later (Farhat et al., 2006; Mahomed et al., 2011).

Peer] reviewing PDF | (2019:10:41848:1:1:NEW 24 May 2020) 
364 Using a TST-10 threshold, it was found that age, male sex, being employed, and low alcohol 365 consumption increased the risk of LTBI, while living in the north zone or suburb zone decreased 366 it. A large number of TB cases reported in Cali are located in the central zone including districts

9 and 11, an area that is characterized by a vulnerable population that lives in conditions of overcrowding, malnutrition, and drug use, and living in zones distant from this point reduced the LTBI risk. On the other hand, our data indicate that after 30 years, the risk of LTBI increases significantly compared with the 14-19 years age group. This is in agreement with other studies where they report a high LTBI prevalence with advanced age (Belo \& Naidoo, 2017; Chen et al., 2015; Gao et al., 2015; Lee et al., 2014; Yap et al., 2018). It is unknown whether the increase in age is the risk factor for acquiring LTBI (Lee et al., 2014) or if the increase in age from 30-39 years reflects a cumulative exposure to people with TB within the community, allowing the development of a detectable immune response against M. tuberculosis infection (Belo \& Naidoo, 2017; do Prado et al., 2017; Gao et al., 2015).

It was found that the LTBI prevalence in males was significantly higher than that in females, especially in the 40-49 years age group. This finding matches those observed a in rural population of China and community-based studies in South Africa and Peru showing epidemiological differences in LTBI prevalence based on sex (Chen et al., 2015; Martinez et al., 2013; Ncayiyana et al., 2016). This is consistent with the ratio (2:1) between males and females observed in TB epidemiological studies (Rhines, 2013). Two possible explanations are proposed: 1) a large proportion of females remain at home and are less likely to be exposed compared to males who have more active social responsibilities (Gao et al., 2015; Kizza et al., 2015), and 2) there is a differential susceptibility to M. tuberculosis infection or predisposition to delayed-type hypersensitivity responsiveness that is dependent on sex (Verhagen et al., 2012). Being employed was associated with an increased LTBI risk. One possible explanation is that the transmission of $M$. tuberculosis occurs in spaces where the working population is exposed, e.g., public transport, which is overcrowded and has little ventilation, increasing the possibility of acquiring $M$. tuberculosis infection between people who often use this type of transport to travel long distances to their work and are repeatedly exposed (Oni et al., 2012). In support of these findings, sex and employment status showed a significant association $(p=0.000)$. In fact, $63 \%$ of females (mostly housewives) were unemployed, while $73 \%$ of males worked outside the home.

Our results show an increase in the risk of TST positivity in light drinkers compared to nondrinkers. Previous studies have shown that, dependent on the amount consumed, alcohol intake is associated with an impaired immune system, increasing susceptibility to respiratory infections such as pneumonia and tuberculosis(Happel \& Nelson, 2005; Rehm et al., 2009; Silva et al., 2018). The relationship between low levels of alcohol consumption and TB risk remains unclear. Soh et al. (2017), in a cohort of middle-aged and elderly Chinese adults, found that lowdose intake of alcohol (monthly to weekly frequency) was associated with a lower risk of TB compared to nondrinkers, but their observation was limited only to nonsmokers. In contrast, in current smokers the consumption of alcohol at low levels did not show any protective effect for the development of TB, but the intake of two or more drinks daily acted synergistically with smoking to increase the TB risk. Similarly, in a study of household and community contacts in India, it was observed that male sex, alcohol consumption and smoking were risk factors for TST positivity. In the multivariate analyses, these three variables also showed an association with LTBI risk [OR $=3.93,95 \%$ CI 1.3-11.9] (Narasimhan et al., 2017). These studies suggest that 
410 alcohol and smoking are strongly correlated. In the present study, a low proportion of individuals 411 smoked (11.5\%), so the influence of this factor on the findings was ruled out. The small number 412 of participants with moderate and high alcohol consumption could make comparisons between 413 the categories difficult, hiding any possible association with TST positivity. Given the low rate 414 of TST positivity, the lack of reactivity due to the immunosuppressive effects of alcohol cannot 415 be ruled out.

416

When the TST-15 threshold was used, results similar to those observed with TST-10 were found. Being male and having low alcohol consumption increased the LTBI risk. In contrast, residing in the north zone or suburb zone and having a secondary education level decreased risk within the model. The association between a higher level of education and a reduction in the LTBI risk can be explained by an improvement in the quality of life of individuals and awareness of health risks dependent on lifestyle habits, and thus increased efforts to reduce their exposure to recognized TB risk factors such as poverty, overcrowding, smoking, and malnutrition (Lonnroth et al., 2009). These findings coincide with the results found in other population-based studies in China, Singapore and South Africa (Chen et al., 2015; Ncayiyana et al., 2016; Yap et al., 2018). The average induration size, using both TST-10 and TST-15 thresholds, was above the cut-off points, allowing us to rule out any possible effects of BCG vaccination or cross-reactivity with nontuberculous mycobacteria (Borroto et al., 2011). This suggests that the threshold of $\geq 10 \mathrm{~mm}$ in the city is a useful tool to confirm $M$. tuberculosis infection in agreement with the recommendation of the CDC (ATS, 2000), while the threshold $\geq 15 \mathrm{~mm}$ can be used as an increased risk indicator for the development of TB in asymptomatic individuals (Ministry of Health, 2010). In support of this recommendation, a cross-sectional study in the Ethiopian population (TB incidence: 164/100,000 inhabitants) using a threshold TST-10 showed that the average TST induration size in community controls was $7.9 \mathrm{~mm}$, which was less than that observed in our study $(16 \mathrm{~mm})$, while in household contacts and patients with TB, it was 13.6 $\mathrm{mm}$ and $18.1 \mathrm{~mm}$, respectively (Shero et al., 2014).

The TST induration size in the generalized linear model was influenced by the increase in age from 40 years, a higher level of education, residing in the north zone or suburb zone, low alcohol consumption and being underweight, which coincides with the variables previously associated with TST positivity in the logistic models for TST-10 and TST-15, except for the association with BMI $<18.5 \mathrm{~kg} / \mathrm{m}^{2}$. The results found show a negative association between underweight and TST induration, explaining the low average TST induration size observed in these individuals compared with normal weight, overweight or obese individuals. These results contrast with previous studies where it has been observed that a lower BMI is an important risk factor for the development of TB (Hanrahan et al., 2010; Lonnroth et al., 2010; Patra et al., 2014).Additionally, overweight and obesity could decreased the risk of active TB (Hanrahan et al., 2010; Kim et al., 2018; Lin et al., 2018). The relationship between BMI and LTBI risk is not well described (Chen et al., 2015; Saag et al., 2018). Several population-based studies in rural areas of China have shown that overweight and obesity significantly increase the LTBI risk. These studies have also reported a nonsignificant negative association between a lower BMI and LTBI (Chen et al., 2015; Gao et al., 2015). Associations similar to those observed in our study, with crude ORs of 0.18 for TST-10 and 0.35 for TST-15, were found. 
455 There were some limitations of this study. First, its cross-sectional nature did not allow the 456 establishment of temporality or causality between LTBI and the associated factors. Second, 457 individuals from some zones of the city (east and southeast) were not included, which implies selection bias, given that people living in the eastern area have a high TB risk. Third, since there is no gold standard for LTBI diagnosis, the estimation of its prevalence could be affected by TST performance. Fourth, there is a possibility of misclassification of drinkers by a self-report bias and the ability to remember. Fifth, as in any observational study, there could be a residual confounding effect of unknown or unmeasured factors on the associations observed. Despite these limitations, this study had an adequate sample size and statistical power and was the first population-based study of LTBI prevalence and associated risk factors in Colombia, so it provides valuable information in a country with an intermediate TB burden, where BCG is administered at birth.

\section{Conclusions}

The LTBI prevalence in our population without associated comorbidities, as measured using two thresholds TST ( $\geq 10 \mathrm{~mm}$ and $\geq 15 \mathrm{~mm}$ ), was moderate ( $25.3 \%$ and $13.2 \%$, respectively), reflecting a significant TB burden and the ongoing transmission of $M$. tuberculosis in the community. Several risk factors traditionally associated with TB (age, educational status, sex, employment situation, BMI and alcohol consumption) showed an association with the positivity and induration of TST in the three multivariate models. Unexpectedly, a lower BMI $(<18.5$ $\mathrm{kg} / \mathrm{m}^{2}$ ) showed a negative and significant association with TST induration, and the LTBI prevalence in underweight individuals was low. In contrast, studies have shown an increase in TB risk among underweight individuals. Additional studies are required to validate our findings and identify other risk factors associated with LTBI. Given that BCG vaccination does not confer protection against TB in adults, and most people who develop TB in Colombia and other developing countries are vaccinated. The community identification of high-risk groups and prophylactic LTBI treatment to prevent progression to TB could be a cost-effective strategy of great impact.

\section{Acknowledgements}

We thank all participating institutions, directives and staff for your support with this study.

\section{References}

Abubakar I, Drobniewski F, Southern J, Sitch AJ, Jackson C, Lipman M, Deeks JJ, Griffiths C, Bothamley G, Lynn W, Burgess H, Mann B, Imran A, Sridhar S, Tsou C-Y, Nikolayevskyy V, Rees-Roberts M, Whitworth H, Kon OM, Haldar P, Kunst $\mathrm{H}$, Anderson S, Hayward A, Watson JM, Milburn H, Lalvani A, Adeboyeku D, Bari $\mathrm{N}$, Barker J, Booth H, Chua F, Creer D, Darmalingam M, Davidson RN, Dedicoat M, Dunleavy A, Figueroa J, Haseldean M, Johnson N, Losewicz S, Lord J, Moore-Gillon J, Packe G, Pareek M, Tiberi S, Pozniak A, and Sanderson F. 2018. Prognostic value of interferon-y; release assays and tuberculin skin test in predicting the development of active tuberculosis (UK PREDICT TB): a 
500

501

502

503

504

505

506

507

508

509

510

511

512

513

514

515

516

517

518

519

520

521

522

523

524

525

526

527

528

529

530

531

532

533

534

535

536

537

538

539

540

541

542

543

544

prospective cohort study. Lancet Infect Dis 18:1077-1087. 10.1016/S14733099(18)30355-4:

Alzate A, Crespo MDP, Carrasquilla G, Corral R, Sanchez N, and Muñoz A. 1993. Purified Protein Derivative (PPD) and HIV Infection in Cali, Colombia. JAIDS 6:630.

ATS. 2000. Targeted Tuberculin Testing and Treatment of Latent Tuberculosis Infection. Am J Respir Crit Care Med 161:S221-S247. 10.1164/ajrccm.161.supplement_3.ats600:

Barbosa A, Peña O, Valderrama-Aguirre A, and Restrepo H. 2015. Factores de Riesgo para Tuberculosis en Trabajadores de Servicios de Urgencias, en dos Niveles de Atención en Salud. Revista Colombiana de Salud Ocupacional 4:30-33.

Basera TJ, Ncayiyana J, and Engel ME. 2017. Prevalence and risk factors of latent tuberculosis infection in Africa: a systematic review and meta-analysis protocol. BMJ Open 7:e012636. 10.1136/bmjopen-2016-012636:

Belo C, and Naidoo S. 2017. Prevalence and risk factors for latent tuberculosis infection among healthcare workers in Nampula Central Hospital, Mozambique. BMC Infect Dis 17:408. 10.1186/s12879-017-2516-4:

Borroto S, Gamez D, Diaz D, Martinez Y, Ferrer Al, Velasquez Y, Llanes MJ, and Gonzalez E. 2011. Latent tuberculosis infection among health care workers at a general hospital in Santiago de Cuba. Int J Tuberc Lung Dis 15:1510-1514, i. 10.5588/ijtld.10.0333:

Cao D, Zhang Z, Yang Z, Ma S, Sun Z, Duan H, Zhu B, and Zhao F. 2019. The association between tuberculin skin test result and active tuberculosis risk of college students in Beijing, China: a retrospective cohort study. BMC Infectious Diseases 19:619. 10.1186/s12879-019-4238-2:

Chen C, Zhu T, Wang Z, Peng H, Kong W, Zhou Y, Shao Y, Zhu L, and Lu W. 2015. High Latent TB Infection Rate and Associated Risk Factors in the Eastern China of Low TB Incidence. PLoS One 10:e0141511. 10.1371/journal.pone.0141511:

De la Pava E, Salguero B, and Alzate A. 2002. Modelo matemático del riesgo anual de infección tuberculosa en Cali. Rev Panam Salud Publica 11:166-171.

del Corral H, París SC, Marín ND, Marín DM, López L, Henao HM, Martínez T, Villa L, Barrera LF, Ortiz BL, Ramírez ME, Montes CJ, Oquendo MC, Arango LM, Riaño F, Aguirre C, Bustamante A, Belisle JT, Dobos K, Mejía GI, Giraldo MR, Brennan PJ, Robledo J, Arbeláez MP, Rojas CA, and García LF. 2009. IFNy Response to Mycobacterium tuberculosis, Risk of Infection and Disease in Household Contacts of Tuberculosis Patients in Colombia. PLoS One 4:e8257. 10.1371/journal.pone.0008257:

Dheda K, Gumbo T, Gandhi NR, Murray M, Theron G, Udwadia Z, Migliori GB, and Warren R. 2014. Global control of tuberculosis: from extensively drug-resistant to untreatable tuberculosis. Lancet Respir Med 2:321-338. 10.1016/s22132600(14)70031-1:

do Prado TN, Riley LW, Sanchez M, Fregona G, Peres RL, Gonçalves L, Zandonade E, Leite R, Mattos de Souza F, Rajan JV, and Noia EL. 2017. Prevalence and risk factors for latent tuberculosis infection among primary health care workers in Brazil. Cad Saúde Pública 33:1-13. 
545 Farhat M, Greenaway C, Pai M, and Menzies D. 2006. False-positive tuberculin skin

546

547

548

549

550

551

552

553

554

555

556

557

558

559

560

561

562

563

564

565

566

567

568

569

570

571

572

573

574

575

576

577

578

579

580

581

582

583

584

585

586

587

588

589 tests: what is the absolute effect of BCG and non-tuberculous mycobacteria? Int $J$ Tuberc Lung Dis 10:1192-1204.

Gao L, Lu W, Bai L, Wang X, Xu J, Catanzaro A, Cardenas V, Li X, Yang Y, Du J, Sui H, Xia Y, Li M, Feng B, Li Z, Xin H, Zhao R, Liu J, Pan S, Shen F, He J, Yang S, Si H, Wang Y, Xu Z, Tan Y, Chen T, Xu W, Peng H, Wang Z, Zhu T, Zhou F, Liu $\mathrm{H}$, Zhao Y, Cheng S, and Jin Q. 2015. Latent tuberculosis infection in rural China: baseline results of a population-based, multicentre, prospective cohort study. Lancet Infect Dis 15:310-319. 10.1016/s1473-3099(14)71085-0:

Hanrahan CF, Golub JE, Mohapi L, Tshabangu N, Modisenyane T, Chaisson RE, Gray GE, McIntyre JA, and Martinson NA. 2010. Body mass index and risk of tuberculosis and death. AIDS 24:1501-1508. 10.1097/QAD.0b013e32833a2a4a:

Happel KI, and Nelson S. 2005. Alcohol, immunosuppression, and the lung. Proc Am Thorac Soc 2:428-432. 10.1513/pats.200507-065JS:

Hassan MI, and Diab AE. 2014. Detection of latent tuberculosis infection among laboratory personnel at a University Hospital in Eastern Saudi Arabia using an interferon gamma release assay. J Infect Public Health 7:289-295. https://doi.org/10.1016/j.jiph.2013.10.002:

Houben RM, and Dodd PJ. 2016. The Global Burden of Latent Tuberculosis Infection: A Re-estimation Using Mathematical Modelling. PLoS Med 13:e1002152. 10.1371/journal.pmed.1002152:

Huynh KK, Joshi SA, and Brown EJ. 2011. A delicate dance: host response to mycobacteria. Curr Opin Immunol 23:464-472. http://dx.doi.org/10.1016/j.coi.2011.06.002:

Kargi A, Ilgazli AH, Yildiz F, Boyaci H, and Basyigit IE. 2017. Latent tuberculosis infection in healthcare workers at a tertiary care center. Biomedical Research 28:657-662.

Kim SJ, Ye S, Ha E, and Chun EM. 2018. Association of body mass index with incident tuberculosis in Korea. PLoS One 13:e0195104. 10.1371/journal.pone.0195104:

Kizza FN, List J, Nkwata AK, Okwera A, Ezeamama AE, Whalen CC, and Sekandi JN. 2015. Prevalence of latent tuberculosis infection and associated risk factors in an urban African setting. BMC Infectious Diseases 15:165-165. 10.1186/s12879015-0904-1:

Lee SJ, Lee SH, Kim YE, Cho YJ, Jeong YY, Kim HC, Lee JD, Kim JR, Hwang YS, Kim $\mathrm{HJ}$, and Menzies D. 2014. Risk factors for latent tuberculosis infection in close contacts of active tuberculosis patients in South Korea: a prospective cohort study. BMC Infect Dis 14:566. 10.1186/s12879-014-0566-4:

Lesmes Duque M, and Reina L. 2016. Informe anual 2016 Vigilancia en Salud Publica. Cali: Gobernacion del Valle del Cauca.

Lin HH, Wu CY, Wang CH, Fu H, Lonnroth K, Chang YC, and Huang YT. 2018. Association of Obesity, Diabetes, and Risk of Tuberculosis: Two PopulationBased Cohorts. Clin Infect Dis 66:699-705. 10.1093/cid/cix852:

Lonnroth K, Jaramillo E, Williams BG, Dye C, and Raviglione M. 2009. Drivers of tuberculosis epidemics: the role of risk factors and social determinants. Soc Sci Med 68:2240-2246. 10.1016/j.socscimed.2009.03.041: 
590 Lonnroth K, Williams BG, Cegielski P, and Dye C. 2010. A consistent log-linear

591

592

593

594

595

596

597

598

599

600

601

602

603

604

605

606

607

608

609

610

611

612

613

614

615

616

617

618

619

620

621

622

623

624

625

626

627

628

629

630

631

632

633

634

635

relationship between tuberculosis incidence and body mass index. Int $J$ Epidemiol 39:149-155. 10.1093/ije/dyp308:

Mahomed H, Hawkridge T, Verver S, Geiter L, Hatherill M, Abrahams DA, Ehrlich R, Hanekom WA, and Hussey GD. 2011. Predictive factors for latent tuberculosis infection among adolescents in a high-burden area in South Africa. Int $J$ Tuberc Lung Dis 15:331-336.

Martinez L, Arman A, Haveman N, Lundgren A, Cabrera L, Evans CA, Pelly TF, Saito M, Callacondo D, Oberhelman R, Collazo G, Carnero AM, and Gilman RH. 2013. Changes in tuberculin skin test positivity over 20 years in periurban shantytowns in Lima, Peru. Am J Trop Med Hyg 89:507-515. 10.4269/ajtmh.13-0005:

Ministry of Health. 2000. Technical rule for vaccination according to the expanded program of immunizations-PAI. Colombia: Ministry of Health.

Ministry of Health. 2010. Guidelines for Tuberculosis Control in New Zealand 2010. Chapter 8: Diagnosis and Treatment of Latent Tuberculosis Infection. Wellington: Ministry of Health.

Ministry of Health. 2015. External Circular 007. Update of the guidelines for the management of tuberculosis and leprosy in Colombia. External Circular 007. Bogota, D.C: Ministry of Health.

Moran-Mendoza O, Marion SA, Elwood K, Patrick DM, and FitzGerald JM. 2007. Tuberculin skin test size and risk of tuberculosis development: a large population-based study in contacts. Int J Tuberc Lung Dis 11:1014-1020.

Muñoz L, Stagg HR, and Abubakar I. 2015. Diagnosis and Management of Latent Tuberculosis Infection. Cold Spring Harbor perspectives in medicine 5:a017830. 10.1101/cshperspect.a017830:

Narasimhan P, Maclntyre CR, Mathai D, and Wood J. 2017. High rates of latent TB infection in contacts and the wider community in South India. Transactions of The Royal Society of Tropical Medicine and Hygiene 111:55-61.

10.1093/trstmh/trx016:

Ncayiyana JR, Bassett J, West N, Westreich D, Musenge E, Emch M, Pettifor A, Hanrahan CF, Schwartz SR, Sanne I, and van Rie A. 2016. Prevalence of latent tuberculosis infection and predictive factors in an urban informal settlement in Johannesburg, South Africa: a cross-sectional study. BMC Infect Dis 16:661. 10.1186/s12879-016-1989-x:

OMS. 2003. Informes Técnicos 916. Dieta, nutrición y prevención de enfermedades crónicas Ginebra.

Oni T, Gideon HP, Bangani N, Tsekela R, Seldon R, Wood K, Wilkinson KA, Goliath RT, Ottenhoff THM, and Wilkinson RJ. 2012. Smoking, BCG and Employment and the Risk of Tuberculosis Infection in HIV-Infected Persons in South Africa. PLoS One 7:e47072. 10.1371/journal.pone.0047072:

PAHO. 2018. Tuberculosis in the Americas. Washington, D.C: PAHO.

Patra J, Jha P, Rehm J, and Suraweera W. 2014. Tobacco Smoking, Alcohol Drinking, Diabetes, Low Body Mass Index and the Risk of Self-Reported Symptoms of Active Tuberculosis: Individual Participant Data (IPD) Meta-Analyses of 72,684 Individuals in 14 High Tuberculosis Burden Countries. PLoS One 9:e96433. 10.1371/journal.pone.0096433:

PeerJ reviewing PDF | (2019:10:41848:1:1:NEW 24 May 2020) 
636 Rehm J, Samokhvalov AV, Neuman MG, Room R, Parry C, Lonnroth K, Patra J,

637

638

639

640

641

642

643

644

645

646

647

648

649

650

651

652

653

654

655

656

657

658

659

660

661

662

663

664

665

666

667

668

669

670

671

672

673

674

675

676

677

678

679

680

Poznyak V, and Popova S. 2009. The association between alcohol use, alcohol use disorders and tuberculosis (TB). A systematic review. BMC Public Health 9:450. 10.1186/1471-2458-9-450:

Rhines AS. 2013. The role of sex differences in the prevalence and transmission of tuberculosis. Tuberculosis (Edinb) 93:104-107. 10.1016/j.tube.2012.10.012:

Rieder HL, Chadha VK, Nagelkerke NJ, van Leth F, and van der Werf MJ. 2011. Guidelines for conducting tuberculin skin test surveys in high-prevalence countries. Int J Tuberc Lung Dis 15 Suppl 1:S1-25.

Rodríguez DA, Gil NA, and Vera NR. 2010. Situación de la tuberculosis en Colombia, 2007-2008, con énfasis en los casos pediátricos y su asociación con VIH. Infectio 14:195-205.

Saag LA, LaValley MP, Hochberg NS, Cegielski JP, Pleskunas JA, Linas BP, and Horsburgh CR. 2018. Low body mass index and latent tuberculous infection: a systematic review and meta-analysis. Int J Tuberc Lung Dis 22:358-365. 10.5588/ijtld.17.0558:

Sharma SK, Mohanan S, and Sharma A. 2012. Relevance of latent TB infection in areas of high TB prevalence. Chest 142:761-773. 10.1378/chest.12-0142:

Shero KC, Legesse M, Medhin G, Belay M, Bjune G, and Abebe F. 2014. Re-assessing tuberculin skin test (TST) for the diagnosis of tuberculosis (TB) among African migrants in Western Europe and USA. Journal of Tuberculosis Research 2:4.

Silva DR, Munoz-Torrico M, Duarte R, Galvao T, Bonini EH, Arbex FF, Arbex MA, Augusto VM, Rabahi MF, and Mello FCQ. 2018. Risk factors for tuberculosis: diabetes, smoking, alcohol use, and the use of other drugs. J Bras Pneumol 44:145-152.

Sivigila. 2017. Informe de evento Tuberculosis, Colombia. Bogota: Instituto Nacional de Salud.

Soh AZ, Chee CBE, Wang Y-T, Yuan J-M, and Koh W-P. 2017. Alcohol drinking and cigarette smoking in relation to risk of active tuberculosis: prospective cohort study. BMJ Open Respir Res 4:e000247. 10.1136/bmjresp-2017-000247:

Stout JE, Wu Y, Ho CS, Pettit AC, Feng P-J, Katz DJ, Ghosh S, Venkatappa T, and Luo R. 2018. Evaluating latent tuberculosis infection diagnostics using latent class analysis. Thorax 73:1062. 10.1136/thoraxjnl-2018-211715:

Verhagen LM, Hermans PW, Warris A, de Groot R, Maes M, Villalba JA, del Nogal B, van den Hof S, Mughini Gras L, van Soolingen D, Pinelli E, and de Waard JH. 2012. Helminths and skewed cytokine profiles increase tuberculin skin test positivity in Warao Amerindians. Tuberculosis (Edinb) 92:505-512. 10.1016/j.tube.2012.07.004:

Wang L, Turner MO, Elwood RK, Schulzer M, and FitzGerald JM. 2002. A metaanalysis of the effect of Bacille Calmette Guerin vaccination on tuberculin skin test measurements. Thorax 57:804-809.

Watkins RE, Brennan R, and Plant AJ. 2000. Tuberculin reactivity and the risk of tuberculosis: a review. Int J Tuberc Lung Dis 4:895-903.

WHO. 2018a. Colombia Tuberculosis profile. World Health Organzation.

WHO. 2018b. Global tuberculosis report 2018. Geneva: World Health Organization.

Peer] reviewing PDF | (2019:10:41848:1:1:NEW 24 May 2020) 
681 WHO. 2018c. Latent tuberculosis infection: updated and consolidated guidelines for 682 programmatic management. Geneva: World Health Organization.

683 WHO. 2019. Global tuberculosis report 2019. Geneva: World Health Organization.

684 Yap P, Tan KHX, Lim WY, Barkham T, Tan LWL, Chen MI, Wang YT, and Chee CBE.

685

686

687 2018. Prevalence of and risk factors associated with latent tuberculosis in Singapore: A cross-sectional survey. Int J Infect Dis 72:55-62.

688 10.1016/j.jiji.2018.05.004: 


\section{Table $\mathbf{1}$ (on next page)}

Prevalence of LTBI according to sociodemographic and lifestyle habits in the study population and its association with TST induration size $(n=589)$. 


\begin{tabular}{|c|c|c|c|c|c|c|}
\hline \multirow[t]{2}{*}{ Characteristics } & \multirow[t]{2}{*}{$n(\%)$} & \multirow{2}{*}{$\begin{array}{c}\text { TST-10 } \\
\%\end{array}$} & \multirow{2}{*}{$\begin{array}{c}\text { TST-15 } \\
\%\end{array}$} & \multicolumn{3}{|c|}{ TST (millimeters) } \\
\hline & & & & Mean & SD & $P$ \\
\hline \multicolumn{7}{|l|}{ Age (years) } \\
\hline Mean (SD) & $43.8(13.2)$ & & & & & \\
\hline $14-19$ & $31(5.3)$ & 6.5 & 6.5 & 3.42 & 4.20 & \\
\hline $20-29$ & $74(12.6)$ & 13.5 & 5.4 & 4.15 & 4.76 & \\
\hline $30-39$ & $96(16.3)$ & 22.9 & 11.5 & 5.32 & 5.63 & 0.000 \\
\hline $40-49$ & $145(24.6)$ & 31.0 & 13.8 & 6.95 & 6.73 & \\
\hline $50-59$ & $180(30.6)$ & 26.7 & 16.7 & 6.87 & 7.01 & \\
\hline $60-69$ & $63(10.7)$ & 34.9 & 17.5 & 8.05 & 7.82 & \\
\hline \multicolumn{7}{|l|}{ Sex } \\
\hline Male & $118(20.0)$ & 33.9 & 17.8 & 7.03 & 6.81 & 0.267 \\
\hline Female & $471(80.0)$ & 23.1 & 12.1 & 6.04 & 6.49 & \\
\hline \multicolumn{7}{|l|}{ Household SES } \\
\hline 1 & $212(36.0)$ & 22.6 & 9.4 & 5.83 & 5.59 & \\
\hline 2 & $198(33.6)$ & 23.2 & 15.2 & 5.97 & 6.63 & 0.251 \\
\hline 3 & $179(30.4)$ & 30.7 & 15.6 & 7.03 & 7.46 & \\
\hline \multicolumn{7}{|l|}{ Overcrowding } \\
\hline$>3$ person/room & $32(5.4)$ & 25.0 & 15.6 & 6.06 & 6.04 & 0.766 \\
\hline$\leq 3$ person/room & $557(94.6)$ & 25.3 & 13.1 & 6.25 & 6.60 & \\
\hline \multicolumn{7}{|l|}{ Educational status } \\
\hline Primary or less & $215(36.5)$ & 32.1 & 18.6 & 7.58 & 7.32 & 0.001 \\
\hline Secondary & $321(54.5)$ & 21.5 & 10.6 & 5.52 & 6.07 & \\
\hline Postsecondary & $53(9.0)$ & 20.8 & 7.5 & 5.15 & 5.25 & \\
\hline \multicolumn{7}{|c|}{ Employment situation } \\
\hline Employee & $259(44.0)$ & 32.0 & 16.2 & 7.08 & 7.21 & 0.034 \\
\hline Unemployed & $330(56.0)$ & 20.0 & 10.9 & 5.58 & 5.93 & \\
\hline \multicolumn{7}{|l|}{ Zone } \\
\hline North & $334(56.7)$ & 22.2 & 10.8 & 5.63 & 6.13 & \\
\hline Suburb & $183(31.1)$ & 21.3 & 9.3 & 5.71 & 5.37 & 0.001 \\
\hline Central & $72(12.2)$ & 50 & 34.7 & 10.44 & 9.26 & \\
\hline \multicolumn{7}{|l|}{ Physical activity } \\
\hline No & $412(69.9)$ & 23.1 & 12.6 & 5.95 & 6.27 & 0.414 \\
\hline Yes & $177(30.1)$ & 30.5 & 22.2 & 6.92 & 7.17 & \\
\hline \multicolumn{7}{|l|}{ Ever smoked } \\
\hline Yes & $89(15.1)$ & 29.2 & 14.6 & 6.90 & 6.95 & 0.311 \\
\hline No & $500(84.9)$ & 24.6 & 13.0 & 6.12 & 6.50 & \\
\hline \multicolumn{7}{|l|}{ Current smoking } \\
\hline Yes & $68(11.5)$ & 29.4 & 16.2 & 7.00 & 7.37 & 0.641 \\
\hline No & $521(88.5)$ & 24.8 & 12.9 & 6.14 & 6.45 & \\
\hline \multicolumn{7}{|l|}{ Alcohol consumption } \\
\hline High & $6(1.0)$ & 16.7 & 0.0 & 5.33 & 4.23 & \\
\hline Moderate & $35(5.9)$ & 17.1 & 8.6 & 4.46 & 5.77 & \\
\hline Low & $35(5.9)$ & 42.8 & 25.7 & 6.46 & 8.47 & 0.012 \\
\hline None & $513(87.1)$ & 24.8 & 12.9 & 6.16 & 6.44 & \\
\hline
\end{tabular}




\begin{tabular}{lcccccc}
\hline BMI $\left(\mathbf{k g} / \mathbf{m}^{\mathbf{2}}\right)$ & & & & & \\
$<18.5$ & $20(3.4)$ & 5.0 & 5.0 & 3.35 & 3.63 & \\
$\geq 18.5$ a 24.9 & $248(42.1)$ & 22.6 & 12.9 & 5.81 & 6.57 & $\mathbf{0 . 0 2 5}$ \\
$\geq 25$ a 29.9 & $229(38.9)$ & 28.4 & 14.0 & 6.70 & 6.53 & \\
$\geq 30$ & $92(15.6)$ & 29.3 & 14.1 & 6.89 & 6.94 & \\
BCG Scar & & & & & & \\
Yes & $536(91.0)$ & 25.4 & 15.1 & 6.25 & 6.52 & 0.670 \\
No & $53(9.0)$ & 24.5 & 13.1 & 6.13 & 7.03 & \\
\hline \multicolumn{2}{l}{ BCG, Bacillus Calmette-Guérin; BMI, body mass index; TST, Tuberculin Skin Test; CI, } \\
confidence interval; OR, odds ratio; SD, Standard deviation.
\end{tabular}


Table 2 (on next page)

Generalized linear model on risk factors for TST induration size 
1

\begin{tabular}{lcccccccc}
\hline Variables & $* \boldsymbol{\beta}$ & $\mathbf{S D} \boldsymbol{\beta}$ & $\mathbf{9 5 \%} \mathbf{C I}$ & $\boldsymbol{p}$ & $\mathbf{B} \boldsymbol{\beta}$ & $\mathbf{B ~ S D ~} \boldsymbol{\beta}$ & $\mathbf{B ~ 9 5 \% ~ C I ~}$ & $\mathbf{B} \boldsymbol{p}$ \\
\hline Intercept & 1.965 & 0.277 & $1.42 ; 2.51$ & $\mathbf{0 . 0 0 0}$ & 1.965 & 0.293 & $1.35 ; 2.49$ & $\mathbf{0 . 0 0 0}$ \\
Education (secondary) & -0.216 & 0.097 & $-0.40 ;-0.02$ & $\mathbf{0 . 0 2 6}$ & -0.216 & 0.100 & $-0.41 ;-0.02$ & $\mathbf{0 . 0 3 4}$ \\
Education (postsecondary) & -0.312 & 0.151 & $-0.61 ;-0.01$ & $\mathbf{0 . 0 3 9}$ & -0.312 & 0.160 & $-0.66 ;-0.00$ & $\mathbf{0 . 0 5 4}$ \\
BMI (<18.5 kg/m²) & -0.574 & 0.194 & $-0.95 ;-0.19$ & $\mathbf{0 . 0 0 3}$ & -0.574 & 0.215 & $-1.04 ;-0.22$ & $\mathbf{0 . 0 1 5}$ \\
Zone (north) & -0.472 & 0.129 & $-0.72 ;-0.22$ & $\mathbf{0 . 0 0 0}$ & -0.472 & 0.135 & $-0.73 ;-0.20$ & $\mathbf{0 . 0 0 1}$ \\
Zone (suburb) & -0.499 & 1.137 & $-0.77 ;-0.23$ & $\mathbf{0 . 0 0 0}$ & -0.499 & 0.143 & $-0.78 ;-0.22$ & $\mathbf{0 . 0 0 1}$ \\
Alcohol consumption (low) & 0.405 & 0.164 & $0.08 ; 0.73$ & $\mathbf{0 . 0 1 4}$ & 0.405 & 0.175 & $0.03 ; 0.73$ & $\mathbf{0 . 0 2 9}$ \\
Age (30-39 years) & 0.338 & 0.241 & $-0.13 ; 0.81$ & 0.162 & 0.338 & 0.248 & $-0.12 ; 0.86$ & 0.193 \\
Age (40-49 years) & 0.561 & 0.235 & $-0.10 ; 1.02$ & $\mathbf{0 . 0 1 7}$ & 0.561 & 0.245 & $0.08 ; 1.07$ & $\mathbf{0 . 0 5 0}$ \\
Age (50-59 years) & 0.421 & 0.236 & $-0.04 ; 0.89$ & 0.075 & 0.421 & 0.247 & $-0.03 ;-0.93$ & 0.122 \\
Age (60-69 years) & 0.666 & 0.255 & $0.17 ; 1.17$ & $\mathbf{0 . 0 0 9}$ & 0.666 & 0.268 & $0.17 ; 1.20$ & $\mathbf{0 . 0 0 3}$ \\
\hline
\end{tabular}

2 *Standardized Coefficients, SD: Standard deviation; B: Bootstrapped for 5000 samples 


\section{Table $\mathbf{3}$ (on next page)}

Characteristics of the study population and its association with TST-10 and TST-15 positivity. 


\begin{tabular}{|c|c|c|c|c|c|c|c|}
\hline \multirow[t]{2}{*}{ Characteristics } & \multicolumn{4}{|c|}{ TST-10 } & \multicolumn{3}{|c|}{ TST-15 } \\
\hline & $\mathbf{N}$ & $n(\%)$ & OR $(95 \%$ CI $)$ & $p$ & $n(\%)$ & OR $(95 \% C I)$ & $p$ \\
\hline \multicolumn{8}{|l|}{ Age (years) } \\
\hline $14-19$ & 31 & $2(1.3)$ & Reference & & $2(2.6)$ & Reference & \\
\hline $20-29$ & 74 & $10(6.7)$ & $2.26(0.46-11.0)$ & 0.300 & $4(5.1)$ & $0.83(0.14-4.77)$ & 1.00 \\
\hline $30-39$ & 96 & $22(14.8)$ & $4.31(0.95-19.5)$ & 0.042 & $11(14.1)$ & $1.87(0.39-8.97)$ & 0.424 \\
\hline $40-49$ & 145 & $45(30.2)$ & $6.52(1.49-28.5)$ & 0.005 & $20(25.6)$ & $2.32(0.51-10.5)$ & 0.262 \\
\hline $50-59$ & 180 & $48(30.2)$ & $5.27(1.21-22.9)$ & 0.014 & $30(38.5)$ & $2.90(0.65-12.8)$ & 0.143 \\
\hline $60-69$ & 63 & $22(14.8)$ & $7.78(1.69-35.7)$ & 0.003 & $11(14.1)$ & $3.06(0.63-14.7)$ & 0.146 \\
\hline \multicolumn{8}{|l|}{ Sex } \\
\hline Male & 118 & $40(26.8)$ & $1.70(1.10-2.64)$ & 0.016 & $21(26.9)$ & $1.57(0.91-2.72)$ & 0.103 \\
\hline Female & 471 & $109(73.2)$ & Reference & & $57(73.1)$ & Reference & \\
\hline \multicolumn{8}{|l|}{ Household SES } \\
\hline 1 & 212 & $48(32.2)$ & $0.66(0.42-1.04)$ & 0.071 & $20(25.6)$ & $0.56(0.30-1.03)$ & 0.062 \\
\hline 2 & 198 & $46(30.9)$ & $0.68(0.43-1.08)$ & 0.101 & $30(38.5)$ & $0.96(0.55-1.68)$ & 0.895 \\
\hline 3 & 179 & $55(36.9)$ & Reference & & $28(35.9)$ & Reference & \\
\hline \multicolumn{8}{|l|}{ Overcrowding } \\
\hline$>3$ person/room & 32 & $8(5.4)$ & $0.98(0.43-2.24)$ & 0.968 & $5(6.4)$ & $1.23(0.45-3.29)$ & 0.683 \\
\hline$\leq 3 \mathrm{person} / \mathrm{room}$ & 557 & $141(94.6)$ & Reference & & $73(93.6)$ & Reference & \\
\hline \multicolumn{8}{|l|}{$\begin{array}{l}\text { Educational } \\
\text { status }\end{array}$} \\
\hline Postsecondary & 53 & $11(7.4)$ & $0.55(0.27-1.14)$ & 0.106 & $4(5.1)$ & $0.35(0.12-1.05)$ & 0.052 \\
\hline Secondary & 321 & $69(46.3)$ & $0.59(0.39-0.86)$ & 0.006 & $34(43.6)$ & $0.52(0.32-0.85)$ & 0.008 \\
\hline Primary or less & 215 & $69(46.3)$ & Reference & & $40(51.3)$ & Reference & \\
\hline \multicolumn{8}{|l|}{$\begin{array}{l}\text { Employment } \\
\text { situation }\end{array}$} \\
\hline Employee & 259 & $83(55.7)$ & $1.89(1.30-2.75)$ & 0.001 & $42(53.8)$ & $1.58(0.98-2.55)$ & 0.059 \\
\hline Unemployed & 330 & $66(44.3)$ & Reference & & $36(46.2)$ & Reference & \\
\hline \multicolumn{8}{|l|}{ Zone } \\
\hline North & 334 & $74(49.7)$ & $0.29(0.17-0.48)$ & 0.000 & $36(46.2)$ & $0.22(0.12-0.41)$ & 0.000 \\
\hline Suburb & 183 & $39(26.2)$ & $0.27(0.15-0.49)$ & 0.000 & $17(21.8)$ & $0.19(0.09-0.38)$ & 0.000 \\
\hline Central & 72 & $36(24.2)$ & Reference & & $25(32.1)$ & Reference & \\
\hline \multicolumn{8}{|l|}{ Physical activity } \\
\hline No & 412 & $95(63.8)$ & $0.68(0.46-1.01)$ & 0.057 & $52(66.7)$ & $0.83(0.50-1.39)$ & 0.497 \\
\hline Yes & 177 & $541(36.2)$ & Reference & & $26(33.3)$ & Reference & \\
\hline \multicolumn{8}{|l|}{ Ever smoked } \\
\hline Yes & 89 & $26(17.4)$ & $1.27(0.77-2.09)$ & 0.356 & $13(16.7)$ & $1.14(0.60-2.18)$ & 0.680 \\
\hline No & 500 & $123(82.6)$ & Reference & & $65(83.3)$ & Reference & \\
\hline \multicolumn{8}{|l|}{ Current smoking } \\
\hline Yes & 68 & $20(13.4)$ & $1.27(0.72-2.21)$ & 0.407 & $11(14.1)$ & $1.31(0.65-2.62)$ & 0.448 \\
\hline No & 521 & $129(86.6)$ & Reference & & $67(85.9)$ & Reference & \\
\hline \multicolumn{8}{|l|}{$\begin{array}{l}\text { Alcohol } \\
\text { consumption }\end{array}$} \\
\hline High & 6 & $1(0.7)$ & $0.61(0.07-5.25)$ & 0.648 & $0(0.0)$ & ----- & 0.347 \\
\hline Moderate & 36 & $6(4.0)$ & $0.61(0.25-1.49)$ & 0.273 & $3(3.8)$ & $0.62(018-2.06)$ & 0.428 \\
\hline
\end{tabular}




\begin{tabular}{|c|c|c|c|c|c|c|c|}
\hline Low & 35 & $15(10.1)$ & $2.28(1.13-4.59)$ & 0.018 & $9(11.5)$ & $2.34(1.05-5.22)$ & 0.032 \\
\hline None & 513 & $127(85.2)$ & Reference & & $66(84.6)$ & Reference & \\
\hline \multicolumn{8}{|l|}{ BMI (kg/m²) } \\
\hline$<18.5$ & 20 & $1(0.7)$ & $0.18(0.02-1.38)$ & 0.065 & $1(1.3)$ & $0.35(0.04-2.74)$ & 0.301 \\
\hline$\geq 18.5$ a 24.9 & 248 & $56(37.6)$ & Reference & & $32(41.0)$ & Reference & \\
\hline$\geq 25$ a 29.9 & 229 & $65(43.6)$ & $1.35(0.89-2.05)$ & 0.146 & $32(41.0)$ & $1.09(0.65-1.86)$ & 0.732 \\
\hline$\geq 30$ & 92 & $27(18.1)$ & $1.42(0.83-2.44)$ & 0.197 & $13(16.7)$ & $1.11(0.55-2.22)$ & 0.767 \\
\hline \multicolumn{8}{|l|}{ BCG Scar } \\
\hline No & 53 & $13(8.7)$ & $0.96(0.49-1.84)$ & 0.893 & $8(10.3)$ & $1.18(0.53-2.61)$ & 0.677 \\
\hline Yes & 536 & $136(91.3)$ & Reference & & $70(89.7)$ & Reference & \\
\hline
\end{tabular}




\section{Table 4 (on next page)}

LTB prevalence between males and females by age groups using a TST-10 threshold. 
1

\begin{tabular}{|c|c|c|c|c|c|c|c|c|c|c|}
\hline \multirow{3}{*}{$\begin{array}{c}\text { Age } \\
\text { (years) }\end{array}$} & \multicolumn{4}{|c|}{ Male } & \multicolumn{4}{|c|}{ Female } & \multirow{3}{*}{ OR (95\% CI) } & \multirow{3}{*}{$p$} \\
\hline & \multicolumn{4}{|c|}{ TST-positive } & \multicolumn{4}{|c|}{ TST-positive } & & \\
\hline & $\mathbf{N}$ & $n$ & $\%$ & $p$ & $\mathbf{N}$ & $\boldsymbol{n}$ & $\%$ & $p$ & & \\
\hline $14-19$ & 12 & 0 & 0 & & 19 & 2 & 10.5 & & ------ & $0.510^{*}$ \\
\hline $20-29$ & 11 & 0 & 0 & & 63 & 10 & 15.9 & & ------ & 0.155 \\
\hline $30-39$ & 17 & 6 & 35.3 & $\mathbf{0 . 0 0 1}^{\ddagger}$ & 79 & 16 & 20.3 & $0.026^{\ddagger}$ & $2.15(0.69-6.69)$ & 0.181 \\
\hline $40-49$ & 19 & 11 & 57.9 & & 126 & 34 & 27.0 & & $3.72(1.38-10.0)$ & 0.007 \\
\hline $50-59$ & 44 & 16 & 36.4 & & 136 & 32 & 23.5 & & $1.86(0.89-3.86)$ & 0.094 \\
\hline $60-69$ & 15 & 7 & 46.7 & & 48 & 15 & 31.3 & & $1.93(0.59-6.23)$ & 0.274 \\
\hline
\end{tabular}

$2{ }^{*} p$ value was calculated from Fisher's exact test

$3{ }^{\ddagger} p$ value for trend was calculated from Chi-square test 


\section{Table 5 (on next page)}

Risk factors associated with TST-10 positivity using a logistic regression. 
1

\begin{tabular}{lcccccc}
\hline \multicolumn{1}{c}{ Variables } & $\boldsymbol{\beta}$ & Wald & OR $^{*}$ & $\mathbf{9 5 \%}$ CI & $\boldsymbol{p}$ & B $\boldsymbol{p}$ \\
\hline Intercept & -2.007 & 6.670 & & & $\mathbf{0 . 0 1 0}$ & $\mathbf{0 . 0 0 7}$ \\
Sex (male) & 0.540 & 4.420 & 1.71 & $1.04-2.84$ & $\mathbf{0 . 0 3 6}$ & $\mathbf{0 . 0 2 7}$ \\
Employment situation & 0.445 & 4.272 & 1.56 & $1.02-2.38$ & $\mathbf{0 . 0 3 9}$ & $\mathbf{0 . 0 4 0}$ \\
(employee) & & & & & & \\
Zone (north) & -1.153 & 16.185 & 0.32 & $0.18-0.55$ & $\mathbf{0 . 0 0 0}$ & $\mathbf{0 . 0 0 0}$ \\
Zone (suburb) & -1.267 & 16.547 & 0.28 & $0.15-0.52$ & $\mathbf{0 . 0 0 0}$ & $\mathbf{0 . 0 0 0}$ \\
Alcohol consumption (low) & 0.874 & 5.139 & 2.40 & $1.13-5.11$ & $\mathbf{0 . 0 2 3}$ & $\mathbf{0 . 0 3 2}$ \\
Age (30-39 years) & 1.455 & 3.414 & 4.29 & $0.92-20.0$ & 0.065 & $\mathbf{0 . 0 3 4}$ \\
Age (40-49 years) & 1.986 & 6.719 & 7.28 & $1.62-32.7$ & $\mathbf{0 . 0 1 0}$ & $\mathbf{0 . 0 0 8}$ \\
Age (50-59 years) & 1.514 & 3.929 & 4.55 & $1.02-20.3$ & $\mathbf{0 . 0 4 7}$ & $\mathbf{0 . 0 2 5}$ \\
Age (60-69 years) & 2.116 & 7.160 & 8.30 & $1.76-39.1$ & $\mathbf{0 . 0 0 7}$ & $\mathbf{0 . 0 0 4}$ \\
\hline
\end{tabular}

2 *From a multivariate logistic regression model with age, sex, social level, overcrowding, educational

3 status, employment situation, zone, exercise, ever smoking, current smoking, alcohol consumption, BMI

4 and BCG scar.

5 B: Bootstrapped for 5000 samples

6 
Table 6(on next page)

Risk factors associated with TST-15 positivity using a logistic regression. 
1

\begin{tabular}{lcccccc}
\hline \multicolumn{1}{c}{ Variables } & $\boldsymbol{\beta}$ & Wald & OR $^{*}$ & $\mathbf{9 5 \%}$ CI & $\boldsymbol{p}$ & $\mathbf{B} \boldsymbol{p}$ \\
\hline Intercept & -0.421 & 2.011 & & & 0.156 & 0.168 \\
Sex (male) & 0.564 & 3.534 & 1.76 & $0.98-3.17$ & 0.060 & 0.085 \\
Education (secondary) & -0.711 & 7.066 & 0.49 & $0.29-0.83$ & $\mathbf{0 . 0 0 8}$ & $\mathbf{0 . 0 0 8}$ \\
Zone (north) & -1.381 & 19.241 & 0.25 & $0.14-0.47$ & $\mathbf{0 . 0 0 0}$ & $\mathbf{0 . 0 0 0}$ \\
Zone (suburb) & -1.653 & 20.31 & 0.19 & $0.09-0.39$ & $\mathbf{0 . 0 0 0}$ & $\mathbf{0 . 0 0 0}$ \\
Alcohol consumption (low) & 0.845 & 3.619 & 2.33 & $0.98-5.56$ & 0.057 & 0.080 \\
\hline
\end{tabular}

2 *From a multivariate logistic regression model with age, sex, social level, overcrowding, educational

3 status, employment situation, zone, exercise, ever smoking, current smoking, alcohol consumption, BMI

4 and BCG scar.

5 B: Bootstrapped for 5000 samples

6 
Figure 1

Flow chart for the uptake, assessment and clinical diagnosis of infections in the population.

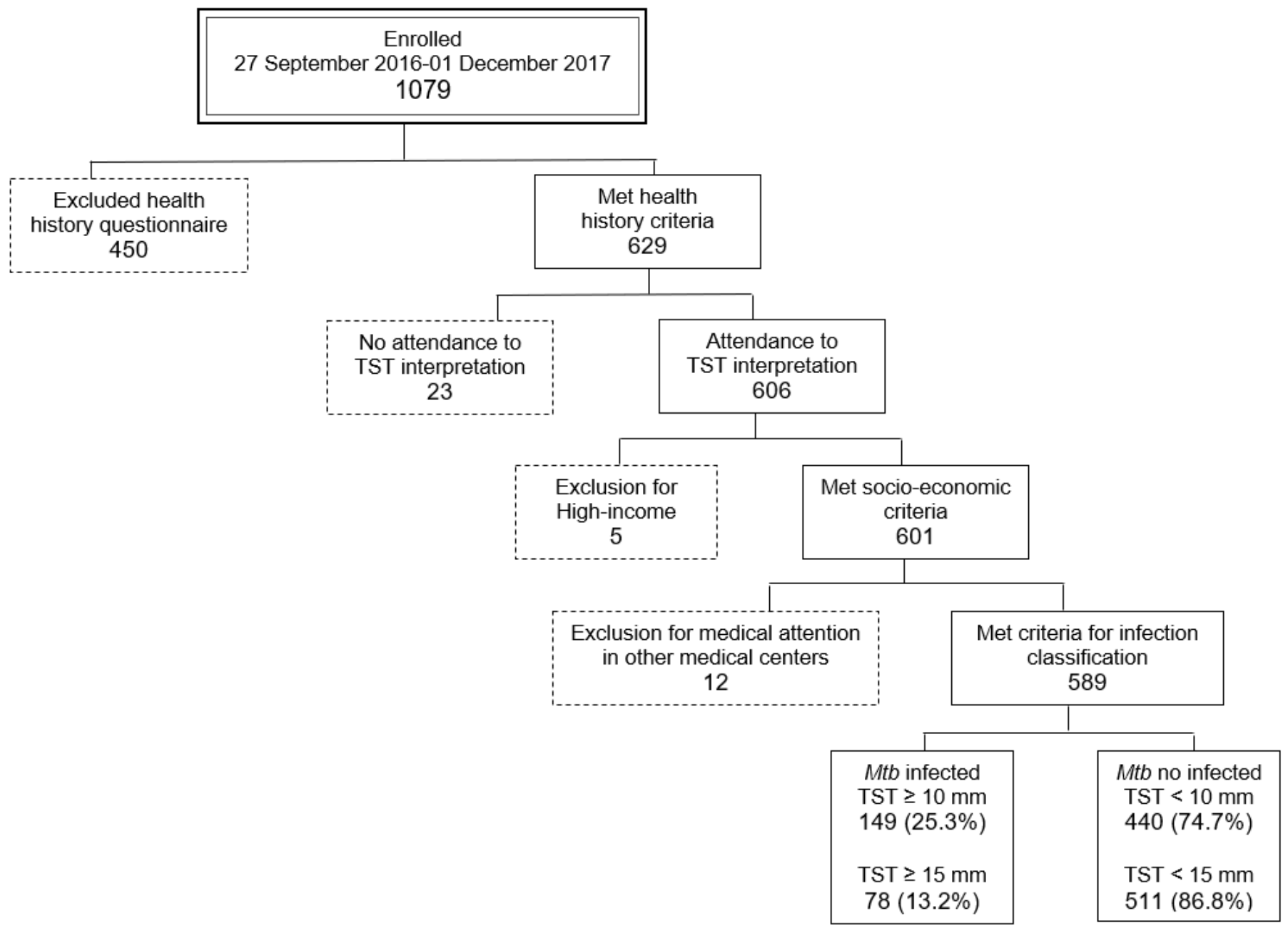


Figure 2

Age-specific trend of LTBI in the study population stratified by sex.

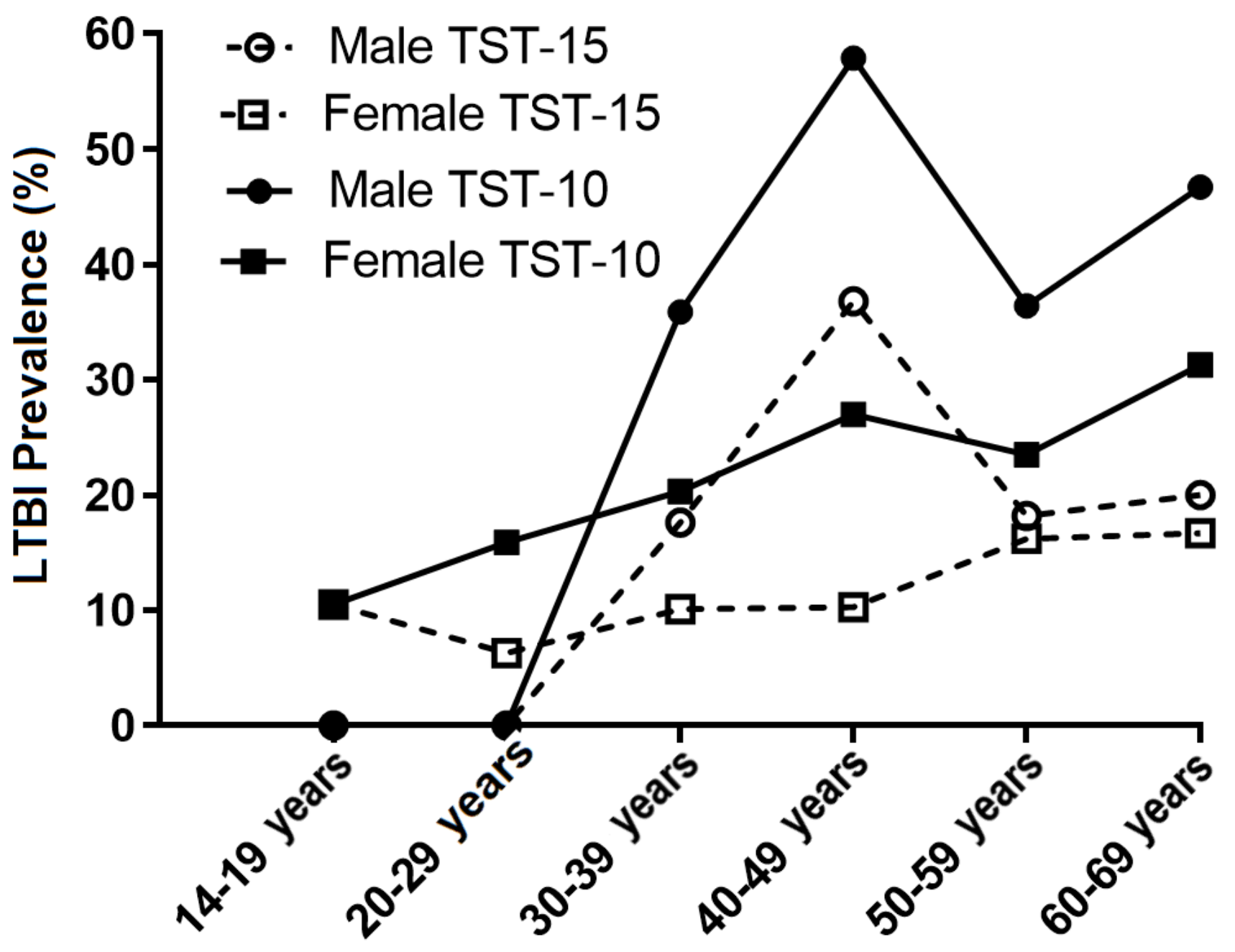

